\title{
Pelatihan Berkomunikasi Lisan Melalui Tata Bahasa Jepang bagi Pemandu Wisata Khusus di Kabupaten Bangli
}

\author{
Anak Agung Ayu Dian Andriyani ${ }^{1}$, Elly Triasih Rahayu², \\ Hartati $^{3}$, I Dewa Ayu Devi Maharani Santika ${ }^{4}$ \\ ${ }^{1,4}$ Universitas Mahasaraswati Denpasar, J1. Kamboja No.11A, Dangin Puri Kangin, Kec. Denpasar \\ Utara, Kota Denpasar, Bali \\ ${ }^{2,3}$ Universitas Jendral Soedirman, Jl. Profesor DR. HR Boenyamin No.708, Dukuhbandong, \\ Grendeng, Kec. Purwokerto Utara, Kabupaten Banyumas, Jawa Tengah \\ Email: agungdianjepang@unmas.ac.id
}

(Diajukan: 01 September 2021, Direvisi: 13 September 2021, Diterima: 11 November 2021)

\begin{abstract}
ABSTRAK
Kegiatan pengabdian dilaksanakan dengan tujuan untuk meningkatkan kemampuan berbahasa Jepang bagi pemandu wisata di Kabupaten Bangli. Kurangnya kemampuan berkomunikasi lisan menggunakan bahasa Jepang, disebabkan karena pemandu wisata khusus belajar secara otodidak.. Hal ini sangat berdampak pada kualitas interaksi dengan wisatawan. Pentingnya dosen dan mahasiswa mengimplementasikan perannya berdasarkan pada Tri darma perguruan tinggi sehingga diadakan kegiatan pengabdian di Kabupateng Bangli dengan tujuan agar pemandu wisata khusus mampu berkomunikasi sesuai tata bahasa Jepang, sehingga dapat memberikan pelayanaan jasa yang sesuai dengan harapan wisatawan Jepang. Pada masa pandemi COVID19, metode yang digunakan saat kegiatan pelatihan dilakukan secara dua arah sehingga terjalin komunikasi yang baik. Kegiatan pengabdian dilakukan secara daring menggunakan aplikasi Zoom. Meskipun tidak dilaksanakan tatap muka, namun pemandu wisatawan khusus sangat antusias mengikuti kegiatan pelatihan selama enam bulan yang dilaksanakan setiap hari minggu dengan dua sesi pembelajaran. Hal ini dibuktikan dengan kehadiran peserta dari berbagai kelompok sadar wisata di kabupaten Bangli dengan usia yang bervariasi tetap tekun mengikuti pelatihan sampai akhir. Hasil dari pelatihan ini memberikan suatu perubahan cara berkomunikasi pemandu wisata khusus dalam menggunakan tata bahasa Jepang dengan cepat dan tepat. Dampak yang telah dirasakan oleh pemandu wisata khusus adalah munculnya rasa percaya diri yang tinggi saat berkomunikasi karena telah memahami tata bahasa yang tepat sehingga maksud dapat tersampaikan dengan baik dan dapat mengimplementasikan etika berkomunikasi lisan menurut budaya masyarakat Jepang.
\end{abstract}

Kata kunci: Tata bahasa, Pemandu Wisata Khusus, Berkomunikasi Lisan, Kabupaten Bangli

\section{ABSTRACT}

Grammar is a basic reference for foreign language learners to communicate orally properly and correctly. The lack of oral communication skills using a foreign language, namely Japanese, is caused by most of the tour guides learning Japanese on a self-taught basis, so that the understanding of the importance of applying grammar in communicating is minimal. This greatly impacts the quality of interaction with tourists. Due to the importance of lecturers and students implementing their roles based on the Tri dharma of higher education, community service activity were held in Bangli Regency with the aim that the special tour guides were able to communicate in accordance with Japanese grammar, so that they could provide services that were in line with the expectations of Japanese tourists. During the pandemic, service activities can be carried out online using the Zoom application. Although it is not carried out face-to-face, the special tourist guides are very enthusiastic about participating in the six-month training activities which are held every Sunday with two learning sessions. This is evidenced by the presence of participants from various tourismaware groups in Bangli district in varying age ranges. They persisted in following the training until the end. Teaching modules that are arranged according to needs provide a change for tour guides in communicating 
using the right Japanese language. This condition is evidenced by the ability to answer questions and make sentences that are in accordance with grammar for the beginner level. By understanding proper grammar, messages can be conveyed properly and can implement oral communication ethics based on Japanese culture.

Keywords: Grammar, Special Tour Guide, Oral Communication, Bangli Regency.

\section{PENDAHULUAN}

Situasi pandemi mengakibatkan sektor pariwisata terpuruk apalagi Bali sebagai destinasi wisatawan lokal maupun mancanegara, yang sebagain besar berpenghasilan dari sektor pariwisata. Namun hal ini tidak menjadi halangan karena seluruh masyarakat dan pemerindah saling bahu mambahu memberikan semangat serta solusi untuk tetap bisa bangkit menghadapi kondisi ini. Salah satu peran Dosen adalah menjalankan Tri Darma perguruan Tinggi, tidak saja dengan mengajar dan melakukan penelitian namun memberikan sunbangsih pikiran, pengalaman dan berbagi ilmu dengan masyarakat terfokus pada pemandu wisata khusus guna meningkatakan kemampuan berbahasa asing salah satunya bahasa Jepang agar mampu berkomunikasi dengan tepat tanpa menimbulkan kelasalahpahaman akibat kurangnya pemahaman dalam penggunaan tata bahasa Jepang.

Berkomunikasi secara lisan merupakan wujud interaksi antar manusia sebagai mahluk sosial. Interaksi yang baik tentu saja mengikuti etika yang tepat. Apalagi berkomunikasi secara lisan menggunakan bahasa Jepang dengan budaya dan tata bahasa yang berbeda dengan bahasa asing lainnya. Belajar bahasa asing tentu harus memahami dengan baik tata bahasa. Karena tata bahasa menjadi acuan seorang pembelajar bahasa dalam menggunakan bahasa dengan baik dan benar. Selain pembelajar bahasa, pemandu wisata khusus merupakan ujung tombak jalannya pariwisata di obyek wisata pada masingmasing Kabupaten Di Bali. Berbekal kemampuan berbahasa Jepang yang kurang karena belajar secara otodidak mengakibatkan kemampuan berbahasa Jepang pemandu wisata khusus di Kabupateng Bangli sangat Kurang. Hal ini memberikan suatu gambaran bahwa peran perguruan tinggi dalam memberikan peningkatan kualitas berbahasa melalui pengabdian kepada amsyaraat sangat diperlukan.

Kegiatan pengabdian kepada masyarakat telah dilakukan oleh berbagai pihak diantaranya pengabdian dalam ranah pendidikan telah dilakukan pada kegiatan pelatihan dengan memanfaatkan aplikasi mendeley Desktop untuk penulisan karya ilmiah bagi para akademisi (Windarto dkk., 2018); selain itu juga pelatihan aplikasi mendeley sangat penting bagi para mahasiswa khsusunya di Fikes Umaha terutama di masa pandemi 
COVID-19 sebagai aplikasi praktis dalam penyusunan daftar pustaka yang sangat dibutuhkan oleh pembelajar dalam menyusun karya tulis (Ngibad, 2020). Apalgi di masa digital seperti sekarang ini kegiatan pengabdian dalam ranah pendidikan dengan memfokuskan pada topic digitalisasi sangat menarik untuk diberikan dalam kegiatan pengabdian kepada masyarakat apalagi dalam penggunaan perangkat berbasis internet dalam pengumpulan data di masa pandemi yang sangat sulit untuk bisa dilakukan dengan cara langsung (Zulfa, Mujibah dan Rajaguguk, 2020).

Kemampuan menggunakan bahasa asing sampai saat ini menjadi kebutuhan penting dalam berbagai ranah kehidupan masyarakat sehingga dengan adanya kebutuhan dalam peningkatan kemampuan dalam berbahasa asing, hal ini memberikan suatu kewajiban para dosen untuk dapat berbagi dengan melakukan pelatihan misalnya, pelatihan bahasa Inggris diperuntukkan bagi guru sekolah dasar (Subekti dan Rumanti, 2020), serta pelatihan bagi kelompok sadar wisata di Desa Ampengan dengan tujuan mendukung program VillageBased Tourism (Ratminingsih dkk., 2020). Tidak saja dalam bentuk pelatihan kebahasaan, kegiatan pengabdian kepada msyarakat khususnya dalam ranah pariwisata dapat dilaksanakan dengan topik yang berbeda yaitu pembelajaran omotenashi sebagai dasar dalam memberikan pelayanan yang sesuai standarnya (Andriyani dan Meidariani, 2020). Pengabdian dengan tujuan untuk meningkatkan kompetensi pramuwisata Goa Gong dalam menghadapi kebiasaan baru dalam ranah pariwisata juga telah dilakukan dengan harapan dapat membantu membangkitkan parwisata Bali (Prasetyo; Agfianto dan Wijayanto, 2021). Kondisi ini juga mengakibatkan banyaknya kegiatan pengabdian bagi kelompok sadar wisata dalam membuat Virtual tour di Desa Sidatapa, Kabupaten Buleleng (Widiastini dkk., 2020) dengan harapan mampu membuat media pariwisata yang berbeda dengan sistem perjalanan sebelumnya. Kegiatan pengandian dalam ranah yang berbina di masa pandemi sangat bervariasi telah dilakukan oleh para Dosen dalam memberikan pembinaan kepada masyarakat meskipun dilakukan secara daring namun interaksi dapat dilaksankan dengan baik. Hal ini dapat dibuktikan pada kegiatan bagi kelompok nelayan tradisional untuk membantu meningkatkan Pengetahuan dan Keterampilan Pengolahan Limbah Ikan (Huwaidi; Panggabean dan Apriliya, 2021). Berbagai kegiatan pengabdian kepada masyarakat di atas memberikan suatu gambaran bahwa peran Dosen berkolaborasi dengan mahasiswa dalam melaknsakana kegiatan pengabdian sangat bermanfaat bagi kehidupan masyarakat dengan berbagai profesi. Kegiatan ini telah membuktikan bahwa para dosen telah melaksanakan kewajibannya sebagai dosen dalam menjalankan tugas sesuai dengan Tri darma perguruan tinggi. Bagaimana halnya dengan kegiatan pelatihan 
bagi pemandu wisata khusus dengan menekankan pada tata bahasa yang baik dan benar? Semoga kegiatan ini dapat memberikan manfaat bagi pemandu wisata khusus di kabupaten Bangli sehingga meningkatkan kualitas pelayanan ketika berinteraksi dengan wisatawan Jepang yang datang ke berbagai Obyek wisata yang ada tanpa harus khawatir dengan kesalahpahaman ketika berkomunikasi menggunakan bahasa Jepang.

\section{METODE}

Kegiatan pengabdian kepada masyarakat diawali dengan menggunakan metode observasi. Artinya dengan metode ini dapat dengan mudah menganalisis situasi dan kondisi yang terjadi di kehidupan masyarakat dengan tepat sehingga dapat menemukan target kegiatan pengabdian yang mempertimbangkan kebutuhan yang sesuai sehingga nantinya ikut membantu mencarikan solusi sesuai dengan kondisi atau situasi yang terjadi di lapangan. Kegiatan observasi dilakukan dengan mengajak para mahasiswa turun ke lapangan dengan menerapkan protokol kesehatan yang ketat untuk bertemu Ketua Kelompok Sadar Wisata dan kepala Sumber daya yang berada di Dinas Pariwisata kabupaten Bangli. Dilanjutkan dengan pengumpulan peserta pelatihan yang tergabung dari kelompok sadar wisata dari berbagai obyek wisata yang berada di Kabupaten Bangli dengan memberikan jadwal pelatihan serta menyiapkan aplikasi zoom untuk digunakan saat pelatihan berlangsung. Selain metode observasi yang dilakukan pada awal kegiatan, kegiatan juga mengadakan pelatihan menggunakan media zoom dengan metode pendekatan secara komunikatif agar interaksi dapat berjalan dengan baik dan ditunjang dengan metode interaksi dua arah antara pemandu wisata khusus selaku peserta dengan team pengabdian. Alat-lat yang digunakan saat memberikan pelatihan tidak sulit karena hanya menggunakan aplikasi zoom. Media ajar selain modul ajar yang telah disusun oleh para dosen dan mahasiswa dengan melihat kebutuhan bagi para pemandu wisata khusus, para pengajar juga telah mempersiapkan materi yang dibuat dalam bentuk PPT agar memudahkan saat memberikan pelatihan. Adapun alasan selama pelatihan menggunakan aplikasi zoom karena sangat praktis apabila digunakan pada kondisi saat ini karena disamping dapat dibagi menjadi beberapa breakout room juga dapat menjangkau berbagai daerah di Bali dengan ditunjang oleh jaringan yang baik. Sebelum pelatihan dimulai, kegiatan pelatihan diawali dengan pengantar dari para dosen dan mahasiswa yang bertugas sesuai jadwal yang telah ditentukan. Setelah interaksi awal dilanjutkan dengan pembelajaran dengan bergabung pada breakout room yang telah ditentukan sesuai absensi. Agar proses pembelajaran berjalan efektif, maka Breakout room dibentuk berdasarkan 
jumlah secara keseluruhan peserta pelatihan yang ikut. Adapun nama kelas tersebut disesuakan dengan nama musim di Jepang yaitu, terdiri dari emapat musim diantaranya kelas, Fuyu (musim dingin), kelas haru (musim semi), kelas natsu (musim panas) dan kelas Aki (musim gugur). Pengajar yang terlibat adalah para dosen dan mahasiswa dimana masing-masing berjumlah 10 orang dengan topik yang sudah disamakan pada setiap pertemuan sesuai dengan rencana pembelajaran yang telah disusun sesuai berdasarkan kebutuhan para pemandu khusus dengan menggunakan kosakata dalam ranah pariwisata yang sering digunakan saat berinteraksi dengan wisatawan Jepang. Kegiatan pengabdian ini berlangsung selama 1 semester dimulai pada bulan akhir Februari sampai dengan awal agustus dengan melibatkan sepuluh dosen dari Program Studi Sastra Jepang FBA Unmas Denpasar dan FIB Universitas Jendral Soedirman serta mengajak sepuluh mahasiswa dari masing-masing Universitas. Adapun mitra yang terlibat diantaranya Kelompok Sadar Wisata Desa Penglipuran serta Dinas Pariwisata Kabupaten Bangli. Berikut dijabarkan secara ringkas metode pelaksanaan kegiatan pelatihan dapat dilihat pada tabel 1 .

Tabel 1. Metode pelaksanaan yang dilakukan

\begin{tabular}{|c|c|c|}
\hline No & Nama Tahapan & Solusi yang ditawarkan \\
\hline 1. & $\begin{array}{l}\text { Observasi } \\
\text { kelapangan }\end{array}$ & $\begin{array}{l}\text { Melaksanakan observasi awal untuk menentukan lokasi } \\
\text { kegiatan pengabdian agar tepat sasaran }\end{array}$ \\
\hline 2. & Perjanjian awal & $\begin{array}{l}\text { Menandatangani kesepakatan dengan Ketua Pokdarwis dan } \\
\text { Dinas Pariwisata Kabupaten Bangli. Penandatanganan surat } \\
\text { kesepakatan perjanjian }\end{array}$ \\
\hline 3. & Jenis Pelatihan & $\begin{array}{l}\text { Pelatihan berkomunikasi lisan menggunakan tata bahasa } \\
\text { Jepang dengan tepat }\end{array}$ \\
\hline 4. & Media & Menggunakan aplikasi zoom \\
\hline 5. & Jumlah Peserta & 25 Peserta \\
\hline 6. & Lama Pelatihan & Enam bulan (satu semester) \\
\hline 7. & Monitoring & $\begin{array}{l}\text { Pendampingan saat berlatih berkomunikasi menggunakan } \\
\text { tata bahasa Jepang yang tepat }\end{array}$ \\
\hline 8. & Evaluasi & $\begin{array}{l}\text { Ujian tertulis dan lisan menggunakan tata bahasa Jepang } \\
\text { dengan baik dan benar ketika memberikan pelayanan jasa } \\
\text { kepada wisatawan Jepang }\end{array}$ \\
\hline
\end{tabular}

\section{HASIL, PEMBAHASAN, DAN DAMPAK}

Banyaknya jumlah kunjungan wisatawan ke salah satu kabupaten di Bali, tepatnya kabupaten Bangli wajib dibarengi dengan adanya peningkatan kualitas berbahasa bagi pemandu wisata khusus yang tergabung dalam kelompok sadar wisata. Salah satu wujud pengabdian kepada masyarakat yang telah dilakukan adalah dengan mengadakan pelatihan 
bagi pemandu wisata khusus dalam menggunakan tata bahasa yang tepat sebagai dasar utama dalam berkomunikasi lisan dengan wisatawan khususnya Jepang. Kegiatan pengabdian kepada masyarakat yang telah dilakukan oleh para dosen Fakultas bahasa Asing Universitas Mahasaraswati Denpasar berkolaborasi dengan Fakultas Ilmu Budaya Universitas Jendral Soedirman serta mengajak para mahasiswa untuk berbagi pengetahaun serta pengalamam kepada para pemandu wisata khusus di kabupaten Bangli. Kemampuan berkomunikasi lisan berdasarkan tata bahasa Jepang yang benar memberikan pengaruh besar terhadap pelayanan jasa yang diberikan. Kegiatan pengabdian yang dilakukan selama enam bulan setiap hari minggu terbagi menjadi dua sesi ini mampu memberikan pengetahuan baru untuk mampu berkomunikasi lisan dengan tepat sesuai tata bahasa yang benar untuk meningkatkan kualitas pelayanan menurut budaya Jepang. Hasil dari pelatihan ini memberikan suatu perubahan dalam memberikan pelayanan jasa karena pemandu wisata dapat berkomunikasi dengan baik dan benar sesuai tata bahasa Jepang dengan cepat dan tepat. Kondisi ini memberikan suatu gambaran peran dari dosen untuk menjalankan kewajibannya dalam kegiatan pengabdian kepada masyarakat dapat bermanfaat bagi kehidupan masyarakat salah satunya pemandu wisata khusus karena dengan kegiatan pengabdian dalam bentuk pelatihan mampu memberikan bekal pengalaman dan menambah wawasan serta kemampuan dalam berkomunikasi lisan menggunakan bahasa Jepang sesuai tata bahasa yang benar dan tepat. Pentingnya kegiatan pengabdian kepada masyarakat juga memberikan peningkatan dalam ranah pendidikan. Contohnya adalah kegiatan yang telah dilakukan dengan tujuan meningkatkan kualitas berbahasa Inggris bagi guru sekolah (Subekti dan Rumanti, 2020). Kegiatan yang sama dalam ranah pariwisata juga telah dilakukan dengan mengadakan pelatihan bagi kelompok sadar wisata di Desa Ampengan yang bertujuan untuk mendukung program Village-Based Tourism (Ratminingsih; Budasi; Adnyani; Suniyasih dan Wulandari, 2020). Kegiatann serupa lainnya adalah pelatihan untuk meningkatkan kualitas pelayanan jasa kepada wisatawan Jepang sebagai wujud pengabdian untuk berbagi demi peningkatakn kualitas pelayanan dalam ranah pariwisata (Andriyani dan Meidariani, 2020). Pelatihan ditujukan kepada pemandu wisata khusus meskipun dilakukan secara daring menggunakan aplikasi zoom dengan media PPT mampu memberikan pemahaman yang baik. Hal ini dibuktikan dengan interaksi secara dua arah dalam menjawab setiap pertanyaan dan latihan yang diberikan saat pelatihan berlangsung. Berikut merupakan beberapa dokumentasi kegiatan saat pelatihan. 


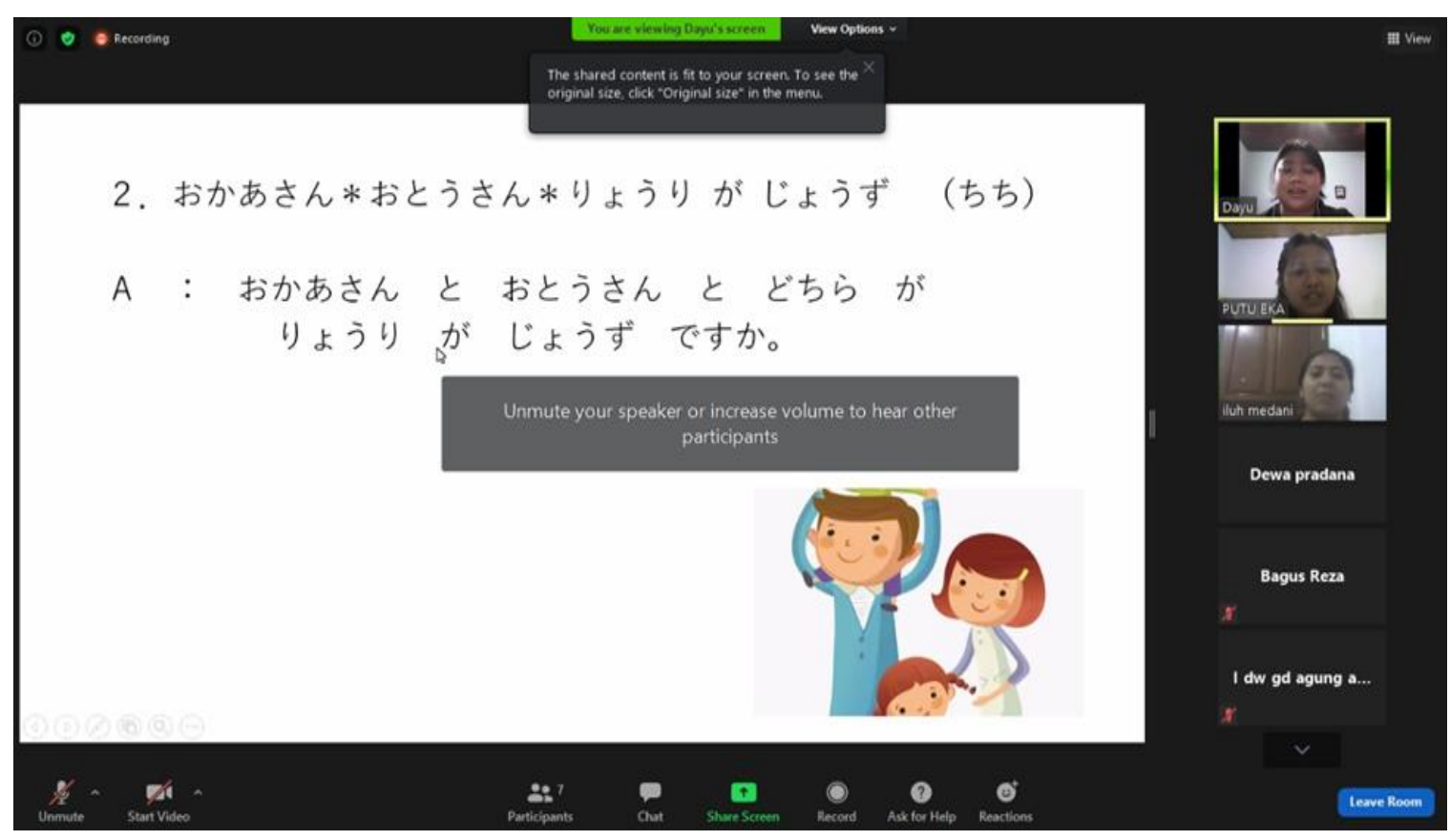

Gambar 1:Kegiatan pembelajaran secara daring pada salah satu kelas di breakout room

Gambar 1 merupakan salah satu kegiatan pelatihan yang telah dilakukan di salah satu room. Pada kegiatan pembelajaran terbagi menjadi empat room dengan menggunakan fasilitas aplikasi breakout room. PPT merupakan media ajar yang digunakan untuk menjelaskan pola-pola dalam bahasa Jepang didukung dengan gambar -gambar menarik guna menarik perhatian dan memberikan inspirasi bagi pemandu wisata dalam membuat kalimat sesuai dengan pola yang diajarkan. Pengajar memberikan materi dengan baik dan memberikan kesempatan bagi peserta untuk membuat kalimat menggunakan pola-pola yang sesuai materi. Meskipun usia para peserta jauh lebih senior dibandingkan para pengajar, namun komunikasi dapat berjalan harmonis. Para peserta pelatihan sangat antusias mengikuti kegiatan meskipun dilakukan secara daring. Berbagai pertanyaan dilontarkan dengan santun sehingga target capaian dapat terealisasikan dengan baik. 


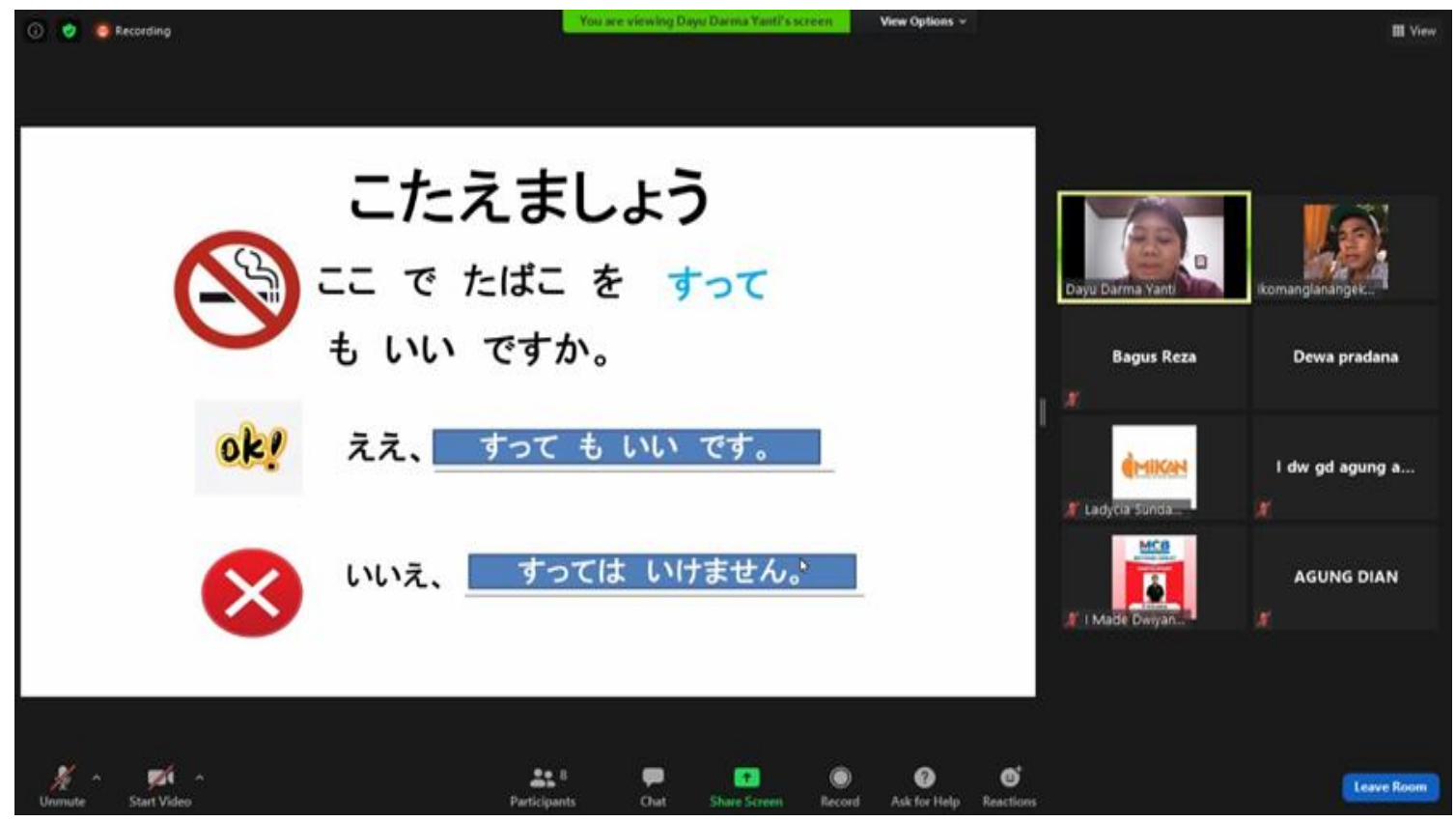

Gambar 2. Salah satu materi ajar yang digunakan saat pelatihan bagi pemandu wisata khusus

Materi yang ditampilkan pada gambar (2) merupakan pola -pola dasar saat menyatakan ijin kepada mitra tutur. Pola ini merupakan bentuk santun yang sering digunakan ketika wisatawan meminta ijin untuk merokok. Pola tersebut mampu dengan baik dipahami oleh pemandu wisatawan khusus di Bangli yang diwujudkan dengan kemampuan peserta dapat dengan baik membuat kalimat-kalimat menggunakan pola ini. Awalnya banyak kesalahan yang telah dilakukan saat mengungkapkan permohonan ijin. Hal ini dikarenakan sistem belajar yang dilakukan hanya secara otodidak. Namun dengan pelatihan ini dapat memeberikan pemahaman yang baik dalam membuat kalimat sesuai tata bahasa Jepang yang baik dan santun. Apalagi dituturkan saat berkomunikai dengan wisatawan sebagai konsumen.

Berbagai pola-pola untuk menunjang komunikasi lisan dalam ranah pariwisata telah diberikan saat pelatihan. Melalui kegiatan monitoring dan evaluasi terlihat secara jelas dampak yang telah dirasakan oleh pemandu wisata khusus di Bangli. Pelatihan ini memberikan peningkatan dalam berkomunikasi menggunakan bahasa Jepang dengan baik dan benar. Sehingga mampu memberikan rasa percaya diri yang tinggi saat berkomunikasi dengan wisatawan Jepang tanpa ada rasa khawatir ataupun takut salah karena saat ini pemandu wisata telah meningkatkan kualitas berbahasa lisan dengan cara memahami tata bahasa yang tepat sehingga maksud dapat tersampaikan dengan baik dan dapat mengimplementasikan etika berkomunikasi lisan menurut budaya masyarakat Jepang. 


\section{SIMPULAN}

Kegiatan pengabdian kepada masyarakat melalui pelatihan bagi pemandu wisata khusus di kabupaten Bangli pada masa pandemi tetap dilaksanakan dengan baik meskipun tidak dilaksanakan secara tatap muka. Pelatihan ini dapat mengumpulkan para pemandu wisata khusu dari berbagai kelompok sadar wisata dari berbagai obyek wisata yang sangat diminati oleh wisatawan lokal maupun mancanegara salah satunya adalah Jepang. Interaksi yang baik dilakukan secara dua arah dengan pendekatan komunikatif memberikan semangat bagi pemandu wisatawan untuk mengikuti kegiatan pelatihan selama enam bulan yang dilaksanakan setiap hari minggu dengan dua sesi pembelajaran. Media ajar secara daring menggunakan aplikasi zoom serta ditunjang dengan modul pembelajaran yang tepat sasaran, maka mampu memberikan pengetahuan baru dan penguasaan tata bahasa Jepang dengan benar. Kemampuan pemandu wisatawan khusus dalam membuat kalimat telah disesuaikan menurut pola-pola yang tepat. Adanya pelatihan ini diharapkan agar pemandu wisatawan khusus untuk tetap konsisten menggunakan pola-pola yang benar meskipun sangat bervariasi, sehingga mampu berkomunikasi lisan sesuai dengan etika tutur budaya masyarakat Jepang terutama dalam ranah pariwisata.

\section{UCAPAKAN TERIMAKASIH}

Pengabdian kepada Masyarakat ini dibiayai oleh Lembaga Pengelola Dana Pendidikan (LPDP) Kementerian Keuangan Republik Indonesia melalui Hibah Riset Inovatif Produktif (RISPRO).

\section{DAFTAR PUSTAKA}

Andriyani, A. A. D., dan Meidariani, N. W. (2020). Pembelajaran Omotenashi Bagi Pramuwisata Travel Standard Japan. WIDYABHAKTI Jurnal Ilmiah Populer, 2(3), 7 12. doi: https://doi.org/10.30864/widyabhakti.v2i3.191

Huwaidi, N., Panggabean, E., \& Apriliya, I. (2021). Peningkatan Pengetahuan dan Keterampilan Pengolahan Limbah Ikan Kepada Kelompok Nelayan Tradisional Secara Daring di Belawan, Sumatera Utara. JPKMI (Jurnal Pengabdian Kepada Masyarakat Indonesia), 2(3), 191-201. doi: https://doi.org/10.36596/jpkmi.v2i3.174

Khairina, N., Perdana, A., Harahap, M. and Siambaton, M. (2020) "Academic Writing : Optimalisasi Mendeley, Grammarly dan Google Translate dalam Pengabdian Webinar Series IKAPASTI-USU”, Prioritas: Jurnal Pengabdian Kepada Masyarakat, 2(02), pp. 1-9. Available at: https://jurnal.harapan.ac.id/index.php/Prioritas/article/view/214 $\quad$ (Accessed: 8 November 2021). 
ngibad, khoirul. (2020). Pelatihan Mendeley secara Online bagi Mahasiswa FIKES UMAHA di Masa Pandemi Covid-19. Jurnal Pengabdian Dan Pemberdayaan Nusantara (JPPNu), 2(1), 110-116. Retrieved from http://journal.unublitar.ac.id/jppnu/index.php/jppnu/article/view/13

Ni Made Ary Widiastini ${ }^{\left(1^{*}\right)}$, Made Aristia Aristia Prayudi ${ }^{(2)}$, Putu Indah Rahmawati ${ }^{(3)}$, I Gede Rasben Dantes ${ }^{(4)}$. (2020). Pelatihan Pembuatan Virtual Tour bagi Kelompok Sadar Wisata Desa Sidatapa, Kabupaten Buleleng, Bali. Bakti Budaya: Jurnal Pengabdian kepada Masyarakat,3(2), 116-131. doi: https://doi.org/10.22146/bb.59518

Prasetyo, J. S., Agfianto, T., dan Wijayanto, N. (2021). Peningkatan Kompetensi Pramuwisata Goa Gong Dalam Era Adaptasi Kebiasaan Baru (Akb) Di Industri Pariwisata. Kumawula: Jurnal Pengabdian Kepada Masyarakat, 4(2), 280-291. doi: https://doi.org/10.24198/kumawula.v4i2.34047

Ratminingsih, N. M., Budasi, I. G., Adnyani, N. P., Suniyasih, N. M., dan Wulandari, P. R. (2020). Pelatihan Bahasa Inggris Bagi Pokdarwis Desa Ambengan Kecamatan Sukasada Dalam Rangka Mendukung Village-Based Tourism. Proceeding Senadimas Undiksha, 384.

Subekti, A., \& Rumanti, M. (2020). Pelatihan Bahasa Inggris untuk Guru Sekolah Dasar di Yogyakarta di Masa Pandemi Covid-19. Jurnal Pengabdian Pada Masyarakat, 5(4), 1077-1086. https://doi.org/10.30653/002.202054.518

Windarto, A. P., Hartama, D., Wanto, A., dan Parlina, I. (2018). Pelatihan Pemanfaatan Mendeley Desktop Sebagai Program Istimewa Untuk Akademisi Dalam Membuat Citasi Karya Ilmiah. AKSIOLOGIYA: Jurnal Pengabdian Kepada Masyarakat, 2(2), 145-150. doi: http://dx.doi.org/10.30651/aks.v2i2.1319

Zulfa, L. L., Mujibah, E. M., \& Rajaguguk, Z. F. (2020). Pelatihan Penggunaan Perangkat Berbasis Internet dalam Pengumpulan Data Penelitian Masa Pandemi COVID-19. Educivilia: Jurnal Pengabdian Pada Masyarakat, 1(2), 143-158. https://doi.org/10.30997/ejpm.v1i2.2835 